Virginia Commonwealth University

vCU Scholars Compass

\title{
Treatment of Cryptococcal Meningitis with Combination Amphotericin B and Flucytosine for Four as Compared with Six Weeks
}

William E. Dismukes , M.D.

University of Alabama - Birmingham

Gretchen Cloud, M.S.

University of Alabama - Birmingham

Harry A. Gallis , M.D.

Duke University

See next page for additional authors

Follow this and additional works at: http://scholarscompass.vcu.edu/intmed pubs

Part of the Medicine and Health Sciences Commons

From The New England Journal of Medicine, Dismukes, W.E., Cloud, G., Gallis, H.A., et al., Treatment of Cryptococcal Meningitis with Combination Amphotericin B and Flucytosine for Four as Compared with Six Weeks, Vol. 317, Page 334, Copyright (C) 1987 Massachusetts Medical Society. Reprinted with permission.

\section{Downloaded from}

http://scholarscompass.vcu.edu/intmed_pubs/52

This Article is brought to you for free and open access by the Dept. of Internal Medicine at VCU Scholars Compass. It has been accepted for inclusion in Internal Medicine Publications by an authorized administrator of VCU Scholars Compass. For more information, please contact libcompass@vcu.edu. 


\section{Authors}

William E. Dismukes , M.D.; Gretchen Cloud , M.S.; Harry A. Gallis , M.D.; Thomas M. Kerkering , M.D.; Gerald Medoff, M.D.; Philip C. Craven , M.D.; Lisa G. Kaplowitz , M.D.; John F. Fisher , M.D.; Clark R.

Gregg , M.D.; Cynthia A. Bowles , R.N.; Smith Shadomy, Ph.D.; Alan M. Stamm , M.D.; Robert B. Diasio, M.D.; Leo Kaufman, Ph.D.; Seng-jaw Soong, Ph.D.; and William C. Blackwelder, Ph.D. 
21. Beem M. Repeated infections with respiratory syncytial virus. J Immunol 1967; 98:1115-22.

22. Hall CB, Douglas RG Jr, Geiman JM. Respiratory syncytial virus infections in infants: quantitation and duration of shedding. J Pediatr 1976; 89:11-5.

23. Idem. Quantitative shedding patterns of respiratory syncytial virus in infants. J Infect Dis 1975; 132:151-6.

24. Kleinbaum DG, Kupper LL, Morgenstern H. Epidemiologic research: principles and quantitative methods. Belmont, Calif.: Lifetime Learning Publications, 1982.

25. Rothman KJ, Boice JD Jr. Epidemiologic analysis with a programmable calculator. Boston: Epidemiology Resources, 1982.

26. Snedecor GW, Cochran WG. Statistical methods. 7th ed. Milwaukee, Wis. American Society of Quality Control, 1980.

27. Hendley JO, Wenzel RP, Gwaltney JM Jr. Transmission of rhinovirus colds by self-inoculation. N Engl J Med 1973; 288:1361-4.
28. Johnson KM, Chanock RM, Rifkind D, Kravetz HM, Knight V. IV. Correlation of virus shedding, serologic response, and illness in adult volunteers. JAMA $1961 ; 176: 663-7$

29. Hall WJ, Hall CB, Speers DM. Respiratory syncytial virus infection in adults: clinical, virologic, and serial pulmonary function studies. Ann Intern Med 1978; 88:203-5

30. Rosenthal R. Experimenter effects in behavioral research. New York: Irvington Publishers, 1976.

31. Hendry RM, Talis AL, Godfrey E, Anderson LJ, Fernie BF, McIntosh $\mathrm{K}$. Concurrent circulation of antigenically distinct strains of respiratory syncytial virus during community outbreaks. J Infect Dis 1986; 153: 291-7

32. Hall CB, McBride JT, Walsh EE, et al. Aerosolized ribavirin treatment of infants with respiratory syncytial viral infection: a randomized double-blind study. N Engl J Med 1983; 308:1443-7.

\title{
TREATMENT OF GRYPTOCOCCAL MENINGITIS WITH COMBINATION AMPHOTERICIN B AND FLUCYTOSINE FOR FOUR AS COMPARED WITH SIX WEEKS
}

\author{
William E. Dismukes, M.D., Gretchen Gloud, M.S., Harry A. Gallis, M.D., \\ Thomas M. Kerkering, M.D., Gerald Medoff, M.D., Philip C. Craven, M.D., \\ Lisa G. Kaplowitz, M.D., John F. Fisher, M.D., Glark R. Gregg, M.D., Cynthia A. Bowles, R.N., \\ Smith Shadomy, Ph.D., Alan M. Stamm, M.D., Robert B. Diasio, M.D., Leo Kaufman, Ph.D., \\ Seng-Jaw Soong, Ph.D., William C. Blackwelder, Ph.D., and the National Institute of \\ Allergy and Infectious Diseases Mycoses Study Group*
}

\begin{abstract}
One hundred ninety-four patients with cryptococcal meningitis were enrolled in a multicenter, prospective, randomized clinical trial to compare the efficacy and toxicity of four as compared with six weeks of combination amphotericin B and flucytosine therapy. Among $91 \mathrm{pa}-$ tients who met preestablished criteria for randomization, cure or improvement was noted in 75 percent of those treated for four weeks and in 85 percent of those treated for six weeks. The estimated relapse rate for the fourweek regimen was higher -27 as compared with 16 percent - whereas the incidence of toxic effects for the two regimens was similar - 44 as compared with 43 percent. Among 23 transplant recipients, 4 of 5 treated for four weeks relapsed, leading to the decision to treat the rest of the group for six weeks. Only 3 of the 18 treated for six weeks relapsed. In a third group of 80 patients, the protocol was not followed during the initial four weeks, and these patients were not randomized.
\end{abstract}

VRYPTOCOCGAL meningitis is the most com1 mon form of fungal meningitis in the United States and is an especially important cause of morbidity and mortality among immunocompromised pa-

From the Division of Infectious Diseases, Department of Medicine; the Division of Clinical Pharmacology, Department of Pharmacology; and the Department of Biostatistics, University of Alabama at Birmingham School of Medicine, Birmingham; the Mycology Laboratory, Medical College of Virginia, Virginia Commonwealth University, Richmond; the Division of Mycotic Diseases, Centers for Disease Control, Atlanta; and the National Institutes of Health, Bethesda, Md. Address reprint requests to Dr. Dismukes at the Division of Infectious Diseases, University of Alabama School of Medicine, Birmingham, AL 35294.

Supported in part by contracts (NO1 AI 82570 and NO1 AI 52562) with the Clinical and Epidemiological Studies Branch, Microbiology and Infectious Diseases Program, National Institute of Allergy and Infectious Diseases; a grant (RR00032) to the Clinical Research Center, University of Alabama at Birming ham; a grant (CA 13148) to the Comprehensive Cancer Center, University of Alabama at Birmingham; a grant (CA RR00036) to the Clinical Research Center, Washington University School of Medicine; a grant (RR00030) to the Clinical Research Center, Duke University School of Medicine; a grant (RR01346) to the Clinical Research Center, University of Texas Health Science Center-San Antonio; and a grant (RR00065) to the Clinical Research Center, Medical College of Virginia, Virginia Commonwealth University.
Thirty-eight died or relapsed. Multifactorial analysis of pretreatment factors for all 194 patients identified three significant predictors $(P<0.05)$ of a favorable response: headache as a symptom, normal mental status, and a cerebrospinal fluid white-cell count above 20 per cubic millimeter.

These and other findings in this study are consistent with the view that the four-week regimen should be reserved for patients who have meningitis without neurologic complications, underlying disease, or immunosuppressive therapy; a pretreatment cerebrospinal fluid white-cell count above 20 per cubic millimeter and a serum cryptococcal antigen titer below 1:32; and at four weeks of therapy, a negative cerebrospinal fluid India ink preparation and serum and cerebrospinal fluid cryptococcal-antigen titers below 1:8. Patients who do not meet these criteria should receive at least six weeks of therapy. (N Engl J Med 1987; 317:334-41.)

tients. Although various therapeutic regimens have been used in this disease, none has been uniformly effective or without serious toxicity. ${ }^{1,2}$ In 1979, Bennett and his coinvestigators reported that a regimen combining amphotericin B $(0.3 \mathrm{mg}$ per kilogram of body weight per day) and flucytosine (150 mg per kilogram per day) and lasting six weeks was as effective, according to all the criteria studied, as a low-dose regimen of amphotericin $B$ alone ( $0.4 \mathrm{mg}$ per kilogram per day) for 10 weeks. ${ }^{3}$ Critics of this controversial study have argued that the dose chosen for the amphotericin $\mathrm{B}$ regimen was too low, thereby biasing the

*Other members of the National Institute of Allergy and Infectious Diseases Mycoses Study Group are Steven G. Alsip, M.D., Michael S. Saag, M.D., George H. Karam, M.D., Carol A. Kauffman, M.D., George A. Sarosi, M.D., Robert L. Marier, M.D., W. Michael Scheld, M.D., John E. Bennett, M.D., H. Preston Holley, Jr., M.D., John R. Black, M.D., David A. Stevens, M.D., Branch Fields, M.D., Gary A. Roselle, M.D., John R. Perfect, M.D., Dale N. Gerding, M.D., and Richard E. Horton, M.D. 
results in favor of the combination regimen. Cerebrospinal fluid cultures converted from positive to negative more rapidly in patients receiving the combination regimen - usually within 7 to 10 days of the start of treatment. Bennett et al. concluded that combined therapy for six weeks was the "regimen of choice" for cryptococcal meningitis but recognized that the regimen with the greatest efficacy, least toxicity, and lowest cost had yet to be determined. We hypothesized that the duration of combination therapy might be shortened further, from six to four weeks, thus reducing toxicity without at the same time compromising efficacy. The results of a prospective, randomized, multicenter clinical trial to address these issues are reported here.

\section{Methods}

\section{Criteria for Enrollment}

Written informed consent was obtained, and patients were enrolled if either of the following criteria was met: (1) a positive cerebrospinal fluid India ink preparation or tentative identification of Cryptococcus neoformans in culture, or (2) cerebrospinal fluid findings compatible with cryptococcal meningitis plus one of the following: a positive culture or histopathologic study from an extraneural site, a positive latex agglutination test for cryptococcal antigen in serum or cerebrospinal fluid, or histopathologic evidence of central nervous system cryptococcosis. Patients who had relapsed after prior unsuccessful therapy were enrolled if they had received no chemotherapy for at least one month and a positive culture was obtained after the last dose of chemotherapy. Patients were excluded if they had a known allergy to either drug, a white-cell count under 1500 per cubic millimeter, or a platelet count under 30,000 per cubic millimeter, or if they were pregnant.

\section{Initial Treatment Regimen}

During the first four weeks, all the patients were treated with the same regimen. Each patient received intravenous amphotericin B ( $0.3 \mathrm{mg}$ per kilogram per day) for 28 days and oral flucytosine (150 mg per kilogram per day, divided into equal doses every six hours) for 28 days. The dosage of flucytosine was reduced in patients with azotemia in accordance with a standard nomogram. ${ }^{4}$ Patients undergoing hemodialysis received flucytosine $(37.5 \mathrm{mg}$ per kilogram) orally after each dialysis.

\section{Criteria for Randomization}

At the end of four weeks, patients were randomized if they (1) had adhered to the protocol during the first four weeks of therapy - i.e., for no fewer than 24 or more than a total of 32 days of drug, or more than 7 days of low-dose drug, or more than 7 days of high-dose drug; (2) had two negative cultures of both blood and cerebrospinal fluid obtained on treatment days 14 and 21 ; and (3) were in a neurologic state of alert wakefulness.

\section{Random Assignment to the Two Treatment Regimens}

Patients were randomly assigned to either a four-week regimen calling for no additional treatment or a six-week regimen that included two additional weeks of combination therapy (at the same dosages used during the first four weeks) for a total duration of six weeks. Random assignment was conducted with use of the closedenvelope technique. Patients were randomly assigned separately to the treatment regimens according to predetermined risk factors. High-risk patients initially included all recipients of organ transplants, all patients with non-Hodgkin's lymphoma, and all patients whose initial pretreatment blood cultures were positive for $C$. neoformans. ${ }^{5}$ After the first year of the study, recipients of organ transplants were no longer eligible for randomization because of the high relapse rate among those initially assigned to the four-week regimen. From years 2 through 5, all patients with transplants were assigned to six weeks of protocol therapy. Low-risk patients included those with none of the risk factors mentioned above.

\section{Studies to Monitor Toxicity and Efficacy}

Before treatment, the following studies were performed: complete and differential blood counts; a blood-chemistry panel, including tests of liver function; a test for serum cryptococcal antigen; cultures of blood and urine for fungi; a lumbar puncture to obtain cerebrospinal fluid for an India ink preparation and a fungal culture, and to determine the opening pressure, the cell count, levels of glucose and protein, and the cryptococcal-antigen titer; and chest roentgenography. All pretreatment studies were repeated weekly during therapy and one week and 1, 3, 6, and 12 months after therapy. A repeated chest roentgenogram was obtained only if the first was abnormal.

\section{Special Laboratory Studies}

The minimal inhibitory concentration and minimal fungicidal concentration of flucytosine were determined for each $C$. neoformans isolate. ${ }^{6}$ Serum levels of flucytosine and fluorouracil were measured in timed serum specimens by bioassay ${ }^{6}$ and high-pressure liquid chromatography. ${ }^{7}$ Cryptococcal-antigen titers of serum and cerebrospinal fluid aliquots stored and frozen at $-70^{\circ} \mathrm{C}$ were determined by a single reference laboratory (Mycology Division, Fungus Immunology Branch, Centers for Disease Control) using the latex agglutination method ${ }^{8}$ with a single set of standards. The results of determinations of cryptococcal-antigen titers and flucytosine serum levels by local hospitals or reference laboratories before and during therapy for purposes of diagnosis and patient care were not included in the data analysis.

\section{Evaluation}

Before, during, and after treatment, case-report forms were completed by the primary investigators and analyzed by the project biostatisticians. A positive culture for $C$. neoformans from cerebrospinal fluid, brain, or meninges was the reason for retaining all but 14 patients in the study. These 14 patients were retained on the basis of clinical symptoms and signs plus positive cultures of extraneural tissues or fluids (7 patients) and serologic evidence (14 patients). All the patients in the study were evaluated for toxic effects. Clinical responses were evaluated on the basis of symptoms, signs, and the results of cultures performed before, during, and after therapy. Clinical outcomes were defined as follows: cure, a negative cerebrospinal fluid culture at one year; improved, the absence of any evidence of cryptococcosis, but the occurrence of the last follow-up or of death at less than one year; and relapse, the proved recurrence of cryptococcosis after therapy was stopped. Even after a patient relapsed, long-term follow-up was attempted. In addition, deaths among nonrandomized patients were classified either as presumed or proved to be due to cryptococcosis alone (or plus another cause) or as unrelated to cryptococcosis.

\section{Study Design}

Our purpose was to determine whether a four-week regimen of combination therapy would be as effective or nearly as effective as a six-week regimen. Although exact equality of treatments cannot be proved with a statistical test, ${ }^{9}$ we thought that the shorter period of therapy, the lower total dose of amphotericin B, and the briefer hospital stay afforded by the four-week regimen would offer distinct advantages even if that regimen were only as effective, or nearly so, as the six-week regimen. Hence, the study was designed to test the null hypothesis that the probability of relapse within one year in patients on the four-week regimen would exceed that in those on the six-week regimen by at least 0.15 . For a 10 percent Type I error (one-sided, since the hypothesis to be tested was inherently onesided) and 70 percent probability (power) of rejecting the null hypothesis, the required sample size was 92 patients without transplants, divided equally between the two regimens, assuming that the true relapse probability was 0.20 for each regimen. In fact, 91 patients were randomized. A 5 percent Type I error and 90 percent power would have required 196 patients; randomizing that number would have extended the study for at least five more years. 


\section{Statistical Analysis}

The 91 randomized patients without transplants were considered in the primary analysis. The comparability of the two regimens was determined by the chi-square test for categorical variables and by Student's t-test for continuous variables. Since follow-up was less than one year for some patients, relapse probabilities and their standard errors were estimated by survival-analysis techniques. ${ }^{10}$ Predetermined risk groups and treatment regimens were compared by means of the simple difference between estimated relapse probabilities or by a weighted mean of differences within subgroups, with inverses of estimated variances taken as weights.

The total group of 194 patients was included in a second analysis to determine the pretreatment factors in patients with cryptococcal meningitis that were associated with failure and relapse after proper adjustment for the patients' characteristics. The following variables were coded as dichotomous: headache, fever, and other selected clinical symptoms and signs; underlying disease, a hematopoietic disorder, chronic alcoholism, sarcoidosis, and corticosteroid or oth-

Table 1. Number of Patients According to Participating Institutions.

\begin{tabular}{|c|c|}
\hline INSTITUTION & No. of Patients \\
\hline University of Alabama, Birmingham & 41 \\
\hline Duke University & 26 \\
\hline $\begin{array}{l}\text { Medical College of Virginia/ } \\
\text { Virginia Commonwealth University }\end{array}$ & 19 \\
\hline Washington University, St. Louis & 16 \\
\hline University of Texas, San Antonio & 15 \\
\hline University of North Carolina & 13 \\
\hline Medical College of Georgia & 12 \\
\hline Vanderbilt University & 11 \\
\hline University of Michigan & 9 \\
\hline University of Minnesota & 7 \\
\hline Louisiana State University, New Orleans & 7 \\
\hline University of Virginia & 4 \\
\hline $\begin{array}{l}\text { Laboratory of Clinical Investigation, } \\
\text { National Institute of Allergy } \\
\text { and Infectious Diseases }\end{array}$ & 4 \\
\hline Medical University of South Carolina & 4 \\
\hline $\begin{array}{l}\text { Santa Clara Valley Medical Center/ } \\
\text { Stanford University }\end{array}$ & 3 \\
\hline University of Arkansas & 2 \\
\hline University of Cincinnati & 1 \\
\hline Total & 194 \\
\hline
\end{tabular}

er immunosuppressive therapy; age $\leqslant 45$ vs. $>45$ years; hematocrit $\leqslant 30$ vs. $>30$ percent; platelet count $\leqslant 100,000$ vs. $>100,000$ per cubic millimeter; cerebrospinal fluid white-cell count $\leqslant 20$ vs. $>20$ per cubic millimeter; positive or negative fungal culture of blood, cerebrospinal fluid, or other body fluid or site; and positive or negative India ink preparation of cerebrospinal fluid. Mental status was coded on a scale of severity (normal, lethargic, or worse). All other variables were analyzed as means. Associations of multiple factors with the length of time before relapse were addressed by Cox regression analysis. " A similar analysis of the association of the length of time before relapse with clinical observations during the initial four weeks of therapy and laboratory indexes measured at the end of four weeks was performed for the 91 randomized patients. ${ }^{11}$ Correlation of outcome with titers of cryptococcal antigen was investigated by chi-square analysis. Because pretreatment samples were not available for all study patients, no attempt was made to include the results of cryptococcal-antigen testing with other pretreatment factors in the multivariate analyses.

\section{Results}

\section{Study Population}

From November 1978 through July 1983, 194 patients were enrolled by 17 participating institutions (Table 1).

\section{Randomized Patients without Transplants}

Of the 91 patients who met the criteria for randomization after the initial four weeks of protocol therapy, 45 were assigned to the four-week regimen and 46 to the six-week regimen. There were no important differences between the two groups (Table 2), although two patients in the four-week group had the acquired immunodeficiency syndrome (AIDS), whereas none in the six-week group had AIDS.

\section{Patients with Organ Transplants}

Twenty-three patients who had received organ transplants adhered to the protocol; their clinical characteristics are also shown in Table 2. Twenty-two patients had received kidney transplants, and one patient had received a heart transplant. Five patients were initially assigned to the four-week regimen; however, because of relapses in four of them, the 18 other protocol-adherent patients with transplants received six weeks of therapy.

\section{Patients Not Randomized}

Eighty other patients were ineligible for randomization for one or more of the following reasons: death during the first four weeks of therapy (26 patients), abnormal mental status (21), persistently positive cultures after day 14 of therapy (9), evidence of new or progressive cryptococcal disease (7), departure from the protocol because of flucytosine toxicity (15), amphotericin B toxicity (1), drug deviations beyond permissible limits (5), and miscellaneous causes (9). The clinical characteristics of this group were similar to those of the randomized group (Table 2). Note that there were five organ-transplant recipients in the group not randomized, in addition to the 23 protocoladherent patients with transplants described above.

\section{Outcomes}

\section{Randomized Patients without Transplants}

As Table 3 shows, among the total group of 91 randomized patients without transplants, 60 were cured, 13 improved, and 18 relapsed. The estimated relapse rates for the four-week and six-week regimens were 27 percent and 16 percent, respectively. The calculated 90 percent and 80 percent confidence intervals include the hypothesized difference of 15 percent; hence, we cannot reject with a one-sided test, at either the 5 or 10 percent significance levels, the predetermined null hypothesis that the risk of relapse is higher by 15 percent or more with the four-week regimen. Similar conclusions were reached when the two regimens were compared within the predetermined highrisk and low-risk groups. The estimated one-year re- 
lapse rates in the patients predetermined to be at high risk were not significantly higher than those in the low-risk patients within both treatment regimens. The disease-free curves for the two treatment regimens are shown in Figure 1.

\section{Patients with Organ Transplants}

Among the 23 patients with transplants who adhered to the protocol, 16 benefited ( 13 were cured and 3 improved), and 7 relapsed. The disease-free curve for this group of patients is shown in Figure 1. Four of the relapses occurred among the 5 transplant recipients who were treated early in the study for only four weeks, whereas the other three relapses occurred among the 18 transplant recipients treated for six weeks.

\section{Patients Not Randomized}

This group of 80 patients did not adhere to the protocol during the first four weeks of therapy; con-

Table 2. Clinical Characteristics of the Patient Groups.

\begin{tabular}{|c|c|c|c|c|c|}
\hline \multirow[t]{2}{*}{ Characteristic } & RANDC & MIZED & \multirow[t]{2}{*}{$\begin{array}{l}\text { PATIENT GROUP } \\
\text { ORGAN-TRANSPLANT } \\
\text { RECIPIENTS } \\
\text { (PROTOCOL ADHERENT) }\end{array}$} & \multirow[t]{2}{*}{$\begin{array}{c}\text { NOT } \\
\text { RANDOMIZED }\end{array}$} & \multirow[t]{2}{*}{ Total } \\
\hline & $4 w k$ & $6 w k$ & & & \\
\hline No. of patients & 45 & 46 & 23 & 80 & 194 \\
\hline $\begin{array}{l}\text { Age (yr) } \\
\text { Mean } \\
\text { Range }\end{array}$ & $\begin{array}{c}49 \\
10-82\end{array}$ & $\begin{array}{c}53 \\
21-78\end{array}$ & $\begin{array}{c}38 \\
25-61\end{array}$ & $\begin{array}{c}58 \\
16-92\end{array}$ & $\begin{array}{c}52 \\
10-92\end{array}$ \\
\hline $\begin{array}{l}\text { Sex } \\
\quad \text { Male } \\
\text { Female }\end{array}$ & $\begin{array}{l}31 \\
14\end{array}$ & $\begin{array}{l}33 \\
13\end{array}$ & $\begin{array}{r}14 \\
9\end{array}$ & $\begin{array}{l}54 \\
26\end{array}$ & $\begin{array}{r}132 \\
62\end{array}$ \\
\hline $\begin{array}{l}\text { Race } \\
\text { White } \\
\text { Black } \\
\text { Other }\end{array}$ & $\begin{array}{r}34 \\
9 \\
2\end{array}$ & $\begin{array}{r}28 \\
16 \\
2\end{array}$ & $\begin{array}{r}15 \\
8 \\
0\end{array}$ & $\begin{array}{r}50 \\
27 \\
3\end{array}$ & $\begin{array}{r}127 \\
60 \\
7\end{array}$ \\
\hline Relapse after prior therapy & 1 & 0 & 0 & 1 & 2 \\
\hline $\begin{array}{l}\text { Underlying disease } \\
\text { None } \\
\text { Vasculitis } \\
\text { Hematopoietic disorder* } \\
\text { AIDS } \\
\text { Organ-transplant recipient } \\
\text { Diabetes mellitus } \\
\text { Chronic alcoholism } \\
\text { Nonhematopoietic cancer }\end{array}$ & $\begin{array}{r}19 \\
6 \\
15 \\
2 \\
0 \\
5 \\
3 \\
0\end{array}$ & $\begin{array}{r}17 \\
7 \\
14 \\
0 \\
0 \\
9 \\
2 \\
0\end{array}$ & $\begin{array}{r}0 \\
0 \\
1 \\
0 \\
23 \\
5 \\
0 \\
0\end{array}$ & $\begin{array}{r}23 \\
10 \\
22 \\
3 \\
5 \\
14 \\
5 \\
3\end{array}$ & $\begin{array}{r}59 \\
23 \\
52 \\
5 \\
28 \\
33 \\
10 \\
3\end{array}$ \\
\hline $\begin{array}{l}\text { Predetermined risk group } \\
\text { High } \\
\text { Low }\end{array}$ & $\begin{array}{r}8 \\
37\end{array}$ & $\begin{array}{l}10 \\
36\end{array}$ & $\begin{array}{r}23 \\
0\end{array}$ & $\begin{array}{l}29 \\
51\end{array}$ & $\begin{array}{r}70 \\
124\end{array}$ \\
\hline $\begin{array}{l}\text { Receiving corticosteroids or } \\
\text { immunosuppressive drugs }\end{array}$ & 18 & 21 & 23 & 40 & 102 \\
\hline Cryptococcal lung disease & 7 & 8 & 7 & 17 & 39 \\
\hline $\begin{array}{l}\text { Cerebrospinal fluid } \\
\text { India ink }\end{array}$ & & & & & \\
\hline $\begin{array}{l}\text { Positive } \\
\text { Negative } \\
\text { Culture }\end{array}$ & $\begin{array}{l}24 \\
21\end{array}$ & $\begin{array}{l}20 \\
24\end{array}$ & $\begin{array}{l}13 \\
10\end{array}$ & $\begin{array}{l}51 \\
29\end{array}$ & $\begin{array}{r}108 \\
84\end{array}$ \\
\hline $\begin{array}{l}\text { Positive } \\
\text { Negative }\end{array}$ & $\begin{array}{r}44 \\
1\end{array}$ & $\begin{array}{r}42 \\
3\end{array}$ & $\begin{array}{r}20 \\
3\end{array}$ & $\begin{array}{r}74 \\
1\end{array}$ & $\begin{array}{r}180 \\
8\end{array}$ \\
\hline Positive blood cultures & 5 & 8 & 8 & 22 & 43 \\
\hline $\begin{array}{l}\text { Other positive extraneural } \\
\text { cultures }\end{array}$ & 1 & 3 & 8 & 14 & 26 \\
\hline
\end{tabular}

*Hematopoietic disorders included disorders of granulocytes, monocytes, macrophages, lymphocytes, and plasma cells. sequently, no uniform treatment regimen was employed. An effort was made to evaluate all the patients who survived an initial course of any therapy. Outcomes in the 49 survivors were as follows: 23 patients were cured, 19 improved, and 7 relapsed. The other 31 nonrandomized patients died -26 during the first 28 days of therapy, and 5 during therapy that continued beyond 28 days. In these 31 patients, death was proved or presumed to be due to cryptococcosis alone or in addition to another cause. Overall, among the 80 nonrandomized patients, 42 were cured or improved and 38 died or relapsed. The disease-free curve for all the patients not randomized is shown in Figure 1.

\section{Relapses}

Among the 32 patients who relapsed regardless of the treatment regimen, the length of time from the discontinuation of therapy to relapse was one month or less in 13 patients, two to three months in 10 , four to six months in 6, and more than six months in only 3 (Fig. 1). No follow-up data after relapse were available on one patient. Among the other 31,22 were placed on some retreatment regimen, 12 were cured, and 10 died or had persistent disease. The other nine patients with relapse who were not retreated died. In most of these, the cause of death was either underlying disease or sepsis, and persistent cryptococcosis was documented at autopsy.

\section{Factors Predicting Outcome}

The pretreatment factors identified by univariate analysis as predicting a favorable response were a normal mental status $(\mathrm{P}<0.001)$, headache $(P=0.001)$, hematocrit above 30 percent $(P=0.003)$, cerebrospinal fluid white-cell count above 20 per cubic millimeter $(P=0.03)$, absence of underlying disease $(P=0.04)$, platelet count above 100,000 per cubic millimeter $(P=0.04)$, and a negative cerebrospinal fluid India ink preparation $(P=0.04)$. Our predetermined assessment of risk (high and low groups) did not correlate significantly with outcome $(P=0.53)$. Because the pretreatment hematocrit and platelet count were closely related to underlying disease and these factors are not biologically known to be associated with cryptococcal meningitis, these factors were not considered in further analyses. 
Table 3. Outcomes in the Randomized Patients According to Treatment Regimen and Predetermined Risk Group.

\begin{tabular}{|c|c|c|c|c|c|}
\hline \multirow[t]{3}{*}{$\begin{array}{l}\text { ReGIMEN/ } \\
\text { RISK GROUP }\end{array}$} & $\begin{array}{l}\text { No. of } \\
\text { Patients }\end{array}$ & \multicolumn{2}{|c|}{ FaVorable RESPONSE } & \multirow[t]{2}{*}{ RELAPSE } & \multirow[t]{2}{*}{$\begin{array}{l}\text { Estimated RELAPSE } \\
\text { RATE ( } \pm \text { SE)* }\end{array}$} \\
\hline & & CURE & IMPROVEMENT & & \\
\hline & & \multicolumn{2}{|c|}{ no. $(\%)$} & no. $(\%)$ & $\%$ \\
\hline 4 Weeks & 45 & $28(62)$ & $6(13)$ & $11(25)$ & $27 \pm 7 \dagger$ \\
\hline Low risk & 37 & $25(67)$ & $4(11)$ & $8(22)$ & $23 \pm 7$ \\
\hline High risk & 8 & $3(38)$ & $2(25)$ & $3(38)$ & $49 \pm 21$ \\
\hline 6 Weeks & 46 & $32(70)$ & $7(15)$ & $7(15)$ & $16 \pm 6 \dagger$ \\
\hline Low risk & 36 & $28(78)$ & $3(8)$ & $5(14)$ & $14 \pm 6$ \\
\hline High risk & 10 & $4(40)$ & $4(40)$ & $2(20)$ & $25 \pm 15$ \\
\hline Total & 91 & $60(66)$ & $13(14)$ & $18(20)$ & $21 \pm 5$ \\
\hline
\end{tabular}

*Determined by the Kaplan-Meier method.

†Ninety percent confidence intervals for the differences in estimated relapse rates, -4 to 25 percent; 80 percent confidence intervals for the differences in estimated relapse rates, -1 to 21 percent.

In the multiple-regression analysis, significant pretreatment predictors of a favorable response were headache $(P=0.005)$, normal mental status $(\mathrm{P}<0.0001)$, and a cerebrospinal fluid white-cell count above 20 per cubic millimeter $(P=0.04)$. Further investigation of the combinations of these pretreatment factors led us to propose two risk groups among patients with cryptococcal meningitis (Table 4). For example, a patient who was lethargic, had no headache upon presentation, and had a cerebrospinal white-cell count under 20 would have an estimated rate of "cure" of 27 percent.

The effect on outcome of the status of the cerebrospinal fluid culture after two weeks of therapy was assessed independently. Two-week culture results were available for 167 patients. Among the 120 patients who ultimately were cured or improved, cultures were negative at two weeks in 89 percent, whereas among 47 patients who died or relapsed, cultures were negative in 81 percent. Thus, a negative two-

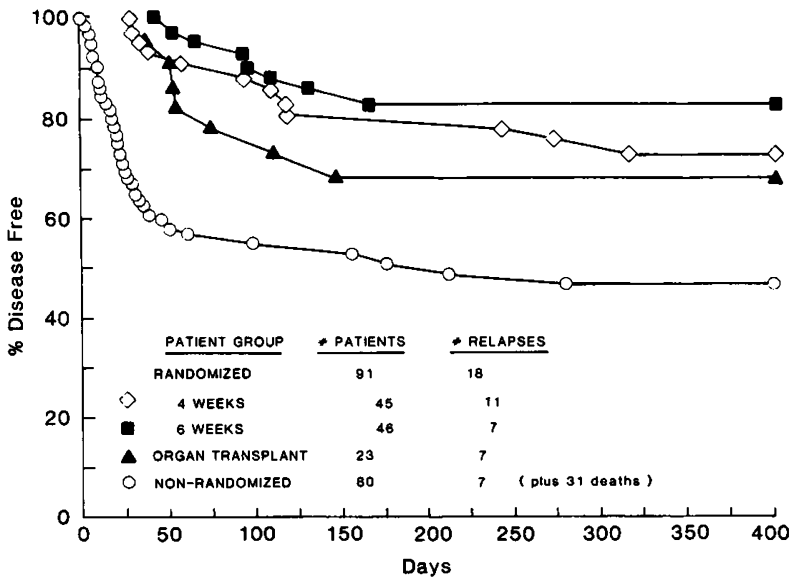

Figure 1. The Probability of Disease-Free Survival in Randomized Patients, Patients with Organ Transplants, and Patients Not Randomized.

For the randomized and transplant groups, each symbol represents one patient relapse; for the group not randomized, each symbol represents either one relapse or one death. week cerebrospinal fluid culture did not predict a favorable outcome $(P=0.16)$.

Since all 91 randomized patients were treated in a similar manner during the first four weeks of therapy, clinical and laboratory factors observed during and at the end of this period were analyzed to determine which would best predict a good outcome. Only two factors - the absence or discontinuation of immunosuppressive therapy and a negative cerebrospinal fluid India ink preparation after four weeks of therapy were identified as significant predictors that there would be no relapse (univariate analysis, $P=0.01$ and $\mathrm{P}=0.002$; multivariate analysis, $\mathrm{P}=0.007$ and $\mathrm{P}=0.02)$.

\section{Flucytosine Susceptibility}

Isolates of $C$. neoformans obtained from 162 patients before treatment or during the first week of treatment were assessed for susceptibility to flucytosine. Ninetyseven percent of the isolates were found to be susceptible (minimal inhibitory concentration, $\leqslant 6.25 \mu \mathrm{g}$ per milliliter). Among 10 isolates from eight patients who relapsed, there was no change in susceptibility in 6 . There was, however, a definite emergence of resistance during therapy in two isolates (minimal inhibitory concentration, $>100 \mu \mathrm{g}$ per milliliter) and possible selection of resistance in the other two. The results of susceptibility testing with flucytosine did not predict the ultimate clinical response.

\section{Toxicity}

The incidence of toxic effects of amphotericin B and flucytosine combined was similar for both treatment regimens. Among the 91 randomized patients, some form of toxic reaction was noted in 44 percent of the patients on the four-week regimen and in 43 percent of the patients on the six-week regimen. Fifty-six percent of the toxic effects appeared during the first two weeks of therapy, and 87 percent during the first four weeks. Among all 194 study patients, one or more major toxic effects developed in 103 patients: azotemia, 51 patients; renal tubular acidosis, 2; leukopenia, 30; thrombocytopenia, 22; diarrhea, 26; nausea or vomiting, 10; and hepatitis, 13. Renal toxicity was ascribed to amphotericin B, whereas bone marrow, gastrointestinal, and hepatic toxic effects were attributed to flucytosine. Two deaths were partly related to amphotericin B-induced azotemia, and three patients died as a direct or indirect consequence of flucytosine toxicity - one of pancytopenia, one of cholestatic hepatitis, and one of diarrhea, ileus, and gastrointestinal bleeding.

Serum flucytosine concentrations measured two or more weeks before the onset of flucytosine toxic reactions in 38 patients were compared with concentrations measured during two or more of the first three weeks of therapy in 47 patients without toxic reactions. The development of toxic effects correlated significantly with concentrations $\geqslant 100 \mu \mathrm{g}$ per milliliter that were present for two or more weeks $(P=0.005)$. 
This correlation was observed for the overall group of patients with toxic effects from flucytosine and for the subgroups with hepatitis $(P=0.004)$ and bone marrow suppression $(P=0.02)$. Peak serum concentrations of fluorouracil, determined in 24 patients with toxic effects from flucytosine and in 26 patients without such effects, did not predict toxicity. More detailed data on toxicity, including the definitions of terms and serum drug concentrations, are provided elsewhere. ${ }^{12}$

\section{Antigen Testing}

Cryptococcal-antigen titers were determined in 1415 samples of serum and cerebrospinal fluid. Pretreatment samples of both serum and cerebrospinal fluid were available in 53 patients. Pretreatment serum samples were available in another 23 patients, and cerebrospinal fluid in another 38 patients. Serum samples obtained both before treatment and at the end of therapy were available in 37 patients, and cerebrospinal fluid samples obtained at both times were available in 38 patients.

As Table 5 shows, pretreatment serum titers $\geqslant 1: 32$ were associated with treatment failure or relapse $(P=0.05)$. In contrast, pretreatment cerebrospinal fluid titers, regardless of the magnitude of the titer, did not predict the outcome. Cryptococcal-antigen titers of less than 1:8 in either serum or cerebrospinal fluid at the end of therapy were associated significantly with cure or improvement $(P=0.04$ and $\mathbf{P}=0.008)$. In addition, the following post-treatment antigen titers determined at least one month after therapy was stopped did correlate with the likelihood of relapse: a serum titer $\geqslant 1: 8(P=0.01)$ and a cerebrospinal fluid titer $\geqslant 1: 8 \quad(\mathrm{P}=$ $0.06)$. Two other important results of cryptococcal-antigen testing not shown in Table 5 were (1) that the magnitude of the pretreatment serum titer correlated significantly with a positive culture of blood for $C$. neoformans (for example, titer $\geqslant 1: 32, \quad \mathbf{P}=0.002$ ), and (2) that pretreatment titers of serum and cerebrospinal fluid $\geqslant 1: 32$ correlated significantly with positive pretreatment cerebrospinal fluid India ink preparations $(\mathrm{P}=0.007$ and $P=0.001$, respectively).

\section{Discussion}

Among the 91 randomized patients, the estimated relapse rates for the four-week and six-week regimens were 27 and 16 percent, respectively. Although these rates appear similar, the difference is such that we could not conclude with a 10 percent level of significance that the four-week regimen was as effec- tive as the six-week regimen. The random assignment of two patients with AIDS to the four-week regimen may have had an effect on the less favorable response in this group (the difference in the rates of relapse between the two regimens is only 6 percent when the patients with AIDS are excluded). Although our data indicate that patients with cryptococcal meningitis are at a higher risk of relapse if treated with a four-week course of combination therapy, it is nevertheless apparent that the four-week regimen is effective in some patients.

The two most important considerations in determining the duration of therapy are probably the underlying disease or immune status of the patient and the severity of the cryptococcal meningitis. Our study and other recent studies shed light on both these factors. Because relapses occurred in four of our first five transplant recipients who were randomly assigned to the four-week regimen, all the transplant recipients who were enrolled subsequently were given a minimum of six weeks of therapy. Overall, among our 28 transplant recipients ( 23 protocol adherent and 5 not randomized), 7 relapsed, but 4 received only four weeks of combination therapy. Watson and coworkers have described 11 cases of cryptococcosis among recipients of renal transplants. ${ }^{13}$ Meningitis that was present in nine cases was treated with combination therapy for 6 weeks in two, for 8 weeks in five, and for 12 weeks in two. Eight of the nine were cured, and only one who was treated for six weeks relapsed. Five other cases of cryptococcal meningitis were reported among 182 heart-transplant recipients at Stanford. ${ }^{14}$ One case was diagnosed at autopsy; of the other four patients, three were cured and one died. Two of the

Table 4. Proposed Risk Groups Based on Prognostic Factors.

\begin{tabular}{|c|c|c|c|c|c|}
\hline $\begin{array}{l}\text { Pretreatment } \\
\text { Mental Status }\end{array}$ & $\begin{array}{l}\text { Headache as } \\
\text { A Presenting } \\
\text { Symptom }\end{array}$ & $\begin{array}{l}\text { Pretreatment } \\
\text { CSF White- } \\
\text { Cell Count* }\end{array}$ & $\begin{array}{c}\text { No. of } \\
\text { Patients } t\end{array}$ & $\begin{array}{c}\text { 1-Yr } \\
\text { Estimated } \\
\text { "CuRE" RATE } \\
( \pm \text { SE }) \ddagger\end{array}$ & $\begin{array}{c}\text { Proposed } \\
\text { RisK GROUP§ }\end{array}$ \\
\hline & & no. $/ \mathrm{mm}^{3}$ & & $\%$ & \\
\hline Normal & Yes & $\leqslant 20$ & 16 & $93 \pm 6$ & Low \\
\hline Normal & Yes & $>20$ & 53 & $88 \pm 5$ & Low \\
\hline Lethargy & Yes & $>20$ & 28 & $85 \pm 7$ & Low \\
\hline Normal & No & $>20$ & 14 & $69 \pm 13$ & High \\
\hline Lethargy & No & $>20$ & 10 & $50 \pm 16$ & High \\
\hline Lethargy & Yes & $\leqslant 20$ & 13 & $47 \pm 16$ & High \\
\hline $\begin{array}{l}\text { Obtundation, } \\
\text { stupor, or coma }\end{array}$ & No & $>20$ & 9 & $53 \pm 18$ & High \\
\hline Normal & No & $\leqslant 20$ & 13 & $33 \pm 18$ & High \\
\hline $\begin{array}{l}\text { Obtundation, } \\
\text { stupor, or coma }\end{array}$ & No & $\leqslant 20$ & 3 & $33 \pm 29$ & High \\
\hline Lethargy & No & $\leqslant 20$ & 9 & $27 \pm 17$ & High \\
\hline $\begin{array}{l}\text { Obtundation, } \\
\text { stupor, or coma }\end{array}$ & Yes & $>20$ & 16 & $17 \pm 18$ & High \\
\hline $\begin{array}{l}\text { Obtundation, } \\
\text { stupor, or coma }\end{array}$ & Yes & $\leqslant 20$ & 2 & 0 & High \\
\hline
\end{tabular}

*CSF denotes cerebrospinal fluid.

†A total of 186 patients had all three pretreatment factors recorded.

$\ddagger$ Determined by the Kaplan-Meier method.

\$The estimated overall "cure" rate for the low-risk group was $88 \pm 3$ percent; for the high-risk group, $38 \pm 7$ percent. 
Table 5. Correlation of Titers of Cryptococcal Antigen in Serum and Cerebrospinal Fluid with the Outcome of Therapy.

\begin{tabular}{ccc}
\hline \hline TITER & $\begin{array}{c}\text { CURE OR } \\
\text { IMPROVEMENT }\end{array}$ & FalluRE OR \\
ReLAPSE & Pumber $(\%)$ & P VALUE*
\end{tabular}

Serum

\begin{tabular}{|c|c|c|c|}
\hline \multicolumn{4}{|l|}{ Before treatment } \\
\hline$<1: 32$ & $22(79)$ & $6(21)$ & \multirow[t]{2}{*}{$0.05 \dagger$} \\
\hline$\geqslant 1: 32$ & $27(56)$ & $21(44)$ & \\
\hline$<1: 128$ & $27(75)$ & $9(25)$ & 0.07 \\
\hline$\geqslant 1: 128$ & $22(58)$ & $18(42)$ & \\
\hline \multicolumn{4}{|l|}{ At end of therapy } \\
\hline$<1: 8$ & $12(92)$ & $1(8)$ & $0.04 \dagger$ \\
\hline$\geqslant 1: 8$ & $25(62)$ & $15(38)$ & \\
\hline No change or increase in titer & $14(74)$ & $5(26)$ & 0.42 \\
\hline At least one tube decrease & $11(61)$ & $7(39)$ & \\
\hline \multicolumn{4}{|l|}{ After therapy $\ddagger$} \\
\hline$<1: 8$ & $36(92)$ & $3(8)$ & \\
\hline$\geqslant 1: 8$ & $12(67)$ & $67(33)$ & $0.01 \dagger$ \\
\hline \multicolumn{4}{|l|}{ Cerebrospinal fluid } \\
\hline \multicolumn{4}{|l|}{ Before treatment } \\
\hline$<1: 32$ & $23(72)$ & $9(28)$ & 0.92 \\
\hline$\geqslant 1: 32$ & $43(73)$ & $16(27)$ & \\
\hline$<1: 128$ & $31(76)$ & $10(24)$ & 0.55 \\
\hline$\geqslant 1: 128$ & $35(70)$ & $15(30)$ & \\
\hline \multicolumn{4}{|l|}{ At end of therapy } \\
\hline$<1: 8$ & $19(90)$ & $2(10)$ & $0.008 \dagger$ \\
\hline$\geqslant 1: 8$ & $19(63)$ & $11(37)$ & \\
\hline No change or increase in titer & $8(73)$ & $3(27)$ & 0.93 \\
\hline At least one tube decrease & $20(74)$ & $7(26)$ & \\
\hline \multicolumn{4}{|l|}{ After therapy $\ddagger$} \\
\hline$<1: 8$ & $46(88)$ & $6(12)$ & 0.06 \\
\hline$\geqslant 1: 8$ & $11(69)$ & $5(31)$ & \\
\hline
\end{tabular}

*By chi-square analysis.

† Statistically significant.

$\ddagger$ At least one month after therapy.

three who were cured received combination therapy. On the basis of these data, we recommend that all transplant recipients who contract cryptococcal meningitis be given at least six weeks of combination therapy with amphotericin $B$ and flucytosine.

Univariate analysis of the effect of pretreatment factors on outcome showed that the presence of one of the underlying diseases listed in Table 2 was associated with a poor outcome $(P=0.04)$. Seventy percent of our patients had one or more underlying diseases, and the most common was a hematopoietic disorder (including AIDS); such a disorder was present in 29 percent and was slightly associated with a poor outcome $(\mathbf{P}=0.13)$. Immunosuppressive therapy was also common among our patients; 53 percent were receiving corticosteroids or some other immunosuppressive drug at the time of diagnosis. Corticosteroid therapy also correlated with a poor outcome $(P=0.09)$. These associations were noted previously by Diamond and Bennett in their retrospective review of 111 cases of cryptococcal meningitis; patients who had a lymphoreticular cancer or who were taking corticosteroids were found to be at a higher risk of dying of active disease during treatment. ${ }^{5}$ These investigators also noted an association between positive pretreatment cultures of blood or other extraneural tissues and the failure of therapy in patients with cryptococcal meningitis ${ }^{5}$; our findings do not support this association. Similarly, Perfect et al. have studied 15 patients with cryptococcemia and concluded that the progress of patients' underlying diseases and the outcome of concomitant infections were more important in determining survival than the presence of cryptococci in the blood. ${ }^{15}$

Cryptococcal disease, including meningitis, has also been extremely difficult to cure in patients with AIDS. Among 27 patients with cryptococcosis and AIDS described by Kovacs and coworkers, 18 had meningitis. ${ }^{16}$ No standardized therapeutic regimen was employed. Treatment was considered a failure in 14, because of either death (9 patients) or persistently positive cultures during therapy or within four weeks of its termination (5 patients). Zuger et al. have described cryptococcosis in another 26 patients with AIDS, 22 of whom had brain or meningeal disease. ${ }^{17}$ Despite the use of several treatment approaches, final outcomes were again not favorable. Among 15 patients who completed their initial treatment regimen, 8 were followed with no further antifungal therapy. Four relapsed and died with active cryptococcosis; three others died of other causes, and only one was reported still alive. Five of our patients had AIDS, and their outcomes were equally poor; only one was free of relapse one year after the discontinuation of therapy. Because of the high relapse rate of cryptococcosis in AIDS and the high mortality associated with relapse, most investigators now recommend maintenance anticryptococcal treatment with weekly amphotericin B.

The severity of the disease also appears to be an important determinant of outcome and consequently of the duration of therapy. In our study, there was a striking correlation between an abnormal mental status at the time of diagnosis and a poor outcome (relapse or death due to active disease). Conversely, patients in whom headache was an initial presenting symptom tended to have favorable outcomes, presumably because this symptom led to early lumbar puncture and diagnosis. Patients with a cerebrospinal fluid white-cell count of less than 20 per cubic millimeter before treatment were more likely to die during therapy or to relapse - an association noted by other investigators. ${ }^{5,18}$ On the basis of our analyses of the predictive value of pretreatment factors, we have proposed two new risk groups among patients with cryptococcal meningitis, in an effort to guide therapy (Table 4). Patients with factors that place them in the high-risk group should receive a minimum of six weeks of combination therapy.

The toxicity of the treatment regimen is another consideration in determining the length of therapy. Bennett and his coworkers noted that the combination regimen was significantly less nephrotoxic than amphotericin B alone. ${ }^{3}$ In our study, the four-week and six-week combination regimens were complicated by toxicity in 44 percent and 43 percent of the cases, respectively. Moreover, flucytosine caused more toxic 
effects than amphotericin $B$, and this difference was positively correlated with flucytosine serum concentrations above $100 \mu \mathrm{g}$ per milliliter. Flucytosine toxicity appeared early in the course of therapy; 49 percent of the toxic reactions occurred during the first two weeks of therapy, and 92 percent within the first four weeks. Similarly, Bennett et al. noted that 92 percent of the adverse effects of flucytosine became apparent during treatment days 10 to $26 .^{3}$ Overall, the fourweek combination regimen was not less toxic than the six-week regimen. Because the toxic effects of flucytosine, especially bone marrow suppression and liver dysfunction, are more likely to occur in patients with sustained elevations of serum concentrations of the drug, and because our protocol required high daily doses of flucytosine (150 mg per kilogram) that may not be tolerated or required by all patients, we recommend weekly monitoring of the peak serum flucytosine concentration and adjustment of the daily dose to maintain serum levels in the range of 50 to $100 \mu \mathrm{g}$ per milliliter.

The results of our testing for cryptococcal antigen suggest that this test has only limited usefulness in predicting the response to therapy and in determining the duration of therapy, and both support and refute the results of previous studies that did not employ a reference laboratory for antigen testing. Diamond and Bennett identified an initial serum or cerebrospinal fluid titer $\geqslant 1: 32$ as a significant risk factor for death during therapy and a post-treatment serum or cerebrospinal fluid titer $\geqslant 1: 8$ as a significant risk factor for relapse. ${ }^{5}$ In a subsequent prospective study, Bennett et al. noted a higher geometric mean cerebrospinal fluid titer, both before and at the end of treatment, among patients in whom therapy failed. ${ }^{3}$ Zuger and colleagues reported similar correlations of antigen titers with outcomes among patients with AIDS. ${ }^{17}$ Our data confirm the previous observations that pretreatment serum titers $\geqslant 1: 32$ and end-of-therapy serum and cerebrospinal fluid titers $\geqslant 1: 8$ are more likely to be associated with failure or relapse. Similarly, serum and cerebrospinal fluid titers $\geqslant 1: 8$ one month or more after treatment are associated with relapse. The important difference in our results from those of earlier studies is the absence of a correlation between pretreatment antigen titers in cerebrospinal fluid and outcome. The latex agglutination test for cryptococcal antigen remains a superb diagnostic tool for patients with suspected cryptococcal meningitis ${ }^{8,19}$; however, we recommend that the results of this test be used with other clinical indexes, not alone, to determine the appropriate duration and potential success of therapy.

In summary, the results of our study are consistent with the view that the duration of combination therapy for cryptococcal meningitis should be based on the immune status or underlying disease of the patient, the severity of the disease, and several serum and cerebrospinal fluid variables. We think the four-week regimen should be reserved for patients with the following characteristics: no underlying disease or immunosuppressive therapy; meningitis that is recognized early and not complicated by neurologic abnormalities; a cerebrospinal fluid white-cell count before treatment $\geqslant 20$ per cubic millimeter; a pretreatment serum cryptococcal antigen titer $<1: 32$; a negative cerebrospinal fluid India ink preparation after four weeks of therapy; and serum and cerebrospinal fluid cryptococcal antigen titers $<1: 8$ at four weeks. All patients who do not meet these criteria should receive at least six weeks of therapy; in addition, some form of long-term maintenance treatment should be considered for patients with AIDS.

We are indebted to Deborah Brooks and Faye Reames for manuscript assistance.

\section{REFERENCES}

1. Sabetta JR, Andriole VT. Cryptococcal infection of the central nervous system. Med Clin North Am 1985; 69:333-44.

2. De Wytt CN, Dickson PL, Holt GW. Cryptococcal meningitis: a review of 32 years experience. J Neurol Sci 1982; 53:283-92.

3. Bennett JE, Dismukes WE, Duma RJ, et al. A comparison of amphotericin $B$ alone and combined with flucytosine in the treatment of cryptococcal meningitis. N Engl J Med 1979; 301:126-31.

4. Schönebeck J, Polak A, Fernex M, Scholer HJ. Pharmacokinetic studies on the oral antimycotic agent 5-fluorocytosine in individuals with normal and impaired kidney function. Chemotherapy 1973; 18:321-36.

5. Diamond RD, Bennett JE. Prognostic factors in cryptococcal meningitis: a study in 111 cases. Ann Intern Med 1974; 80:176-81

6. Shadomy S, Espinel-Ingroff A, Cartwright RY. Laboratory studies with antifungal agents: susceptibility tests and bioassays. In: Lennette EH, Balows A, Hausler WJ Jr, Shadomy HJ, eds. Manual of clinical microbiology. 4th ed. Washington, D.C.: American Society for Microbiology, 1985:991-9.

7. Diasio RB, Wilburn ME, Shadomy S, Espinel-Ingroff A. Rapid determination of serum 5-fluorocytosine levels by high-performance liquid chromatography. Antimicrob Agents Chemother 1978; 13:500-4.

8. Goodman JS, Kaufman L, Koenig MG. Diagnosis of cryptococcal meningitis: value of immunologic detection of cryptococcal antigen. N Engl J Med 1971; 285:434-6.

9. Blackwelder WC. "Proving the null hypothesis" in clinical trials. Controlled Clin Trials 1982; 3:345-53.

10. Kaplan EL, Meier P. Nonparametric estimation from incomplete observations. J Am Stat Assoc 1968; 53:457-81.

11. Cox DR. Regression models and life-tables. J R Stat Soc [B] 1972; 34:187220.

12. Stamm AM, Diasio RB, Dismukes WE, et al. Toxicity of amphotericin B plus flucytosine in 194 patients with cryptococcal meningitis. Am J Med (in press).

13. Watson AJ, Russell RP, Cabreja RF, Braverman R, Whelton A. Cure of cryptococcal infection during continued immunosuppressive therapy. Q J Med 1985; 55:169-72.

14. Britt RH, Enzmann DR, Remington JS. Intracranial infection in cardiac transplant recipients. Ann Neurol 1981; 9:107-19.

15. Perfect JR, Durack DT, Gallis HA. Cryptococcemia. Medicine (Baltimore) $1983 ; 62: 98-109$.

16. Kovacs JA, Kovacs AA, Polis M, et al. Cryptococcosis in the acquired immunodeficiency syndrome. Ann Intern Med 1985; 103:533-8.

17. Zuger A, Louie E, Holzman RS, Simberkoff MS, Rahal JJ. Cryptococcal disease in patients with the acquired immunodeficiency syndrome: diagnostic features and outcome of treatment. Ann Intern Med 1986; 104:234-40.

18. Butler WT, Alling DW, Spickard A, Utz JP. Diagnostic and prognostic value of clinical and laboratory findings in cryptococcal meningitis: a follow-up study of forty patients. N EngI J Med 1964; 270:59-67.

19. Snow RM, Dismukes WE. Cryptococcal meningitis: diagnostic value of cryptococcal antigen in cerebrospinal fluid. Arch Intern Med 1975; 135: $1155-7$. 